\title{
Aggressive Surgical Resection of Enormous Cervical Metastasis from Nasopharyngeal Carcinoma
}

\section{Agresivni kirurški zahvat vađenja velike vratne metastaze iz nazofaringealnog karcinoma}

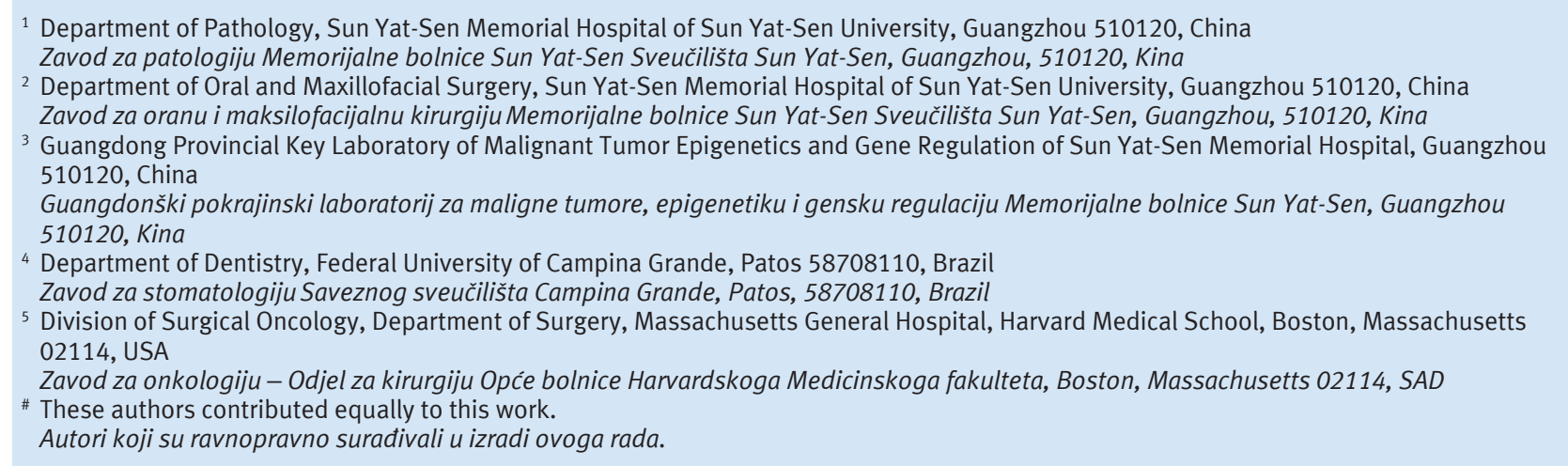

\section{Abstract}

While nasopharyngeal carcinoma (NPC) commonly presents lymphoid metastases, the enormous cervical metastasis causing dysphagia and limitation of neck motion is not a familiar symptom for most of NPC cases. We report a 23-year-old male with undifferentiated carcinoma of the nasopharynx, stage (T3N2M0), who had undergone aggressive surgical resection of bilateral huge cervical mass first followed by concurrent chemo-radiotherapy with cisplatin-based regimens. The postoperative clinical course was uneventful and follow-up, 2 years later, revealed no recurrence of primary lesion and neck metastases. We recommend that aggressive surgical resection may be considered when NPC patients significantly suffer clinical symptoms from a huge cervical metastasis.
Received: December 12, 2018

Accepted: April 11, 2019

Address for correspondence

Dr. Song Fan,

Sun Yat-Sen University, Sun Yat-Sen Memorial Hospital

Department of Oral and Maxillofacial Surgery,

Guangzhou 510120, China.

Telephone: +86 02081332220 ;

fansong8888@163.com or

Professor Eduardo Dias-Ribeiro, Federal University of Campina Grande Department of Dentistry, Patos 58708110, Brazil..

Telephone: +55 83 999031968; eduardodonto@yahoo.com.br

Key words

Nasopharyngeal Carcinoma; Cervical Metastasis; Resection

\section{Introduction}

NPC is one of the most common epithelial malignancies of the head and neck in southern China and it also has a high morbidity rate in some Southeast Asia countries, where the incidence of this disease is 20-30 per 100000 (1,2). Nasopharyngeal region is rich in lymphatic plexus and the epithelium is commonly infiltrated by many small lymphoid cells. Lymphoid metastases are found in almost $90 \%$ of patients at

\section{Uvod}

NPK je jedna od najčešćih epitelnih malignih bolesti glave i vrata u južnoj Kini i ima visoku stopu morbiditeta u nekim zemljama jugoistočne Azije gdje je učestalost te bolesti 20 do 30 stanovnika na $100000(1,2)$. Nazofaringealna regija bogata je limfnim pleksusom, a epitel se obično infiltrira u mnoge male limfne stanice. Limfoidne metastaze nađene su kod gotovo $90 \%$ bolesnika s tom dijagnozom (3, 4). Ra- 
diagnosis $(3,4)$. Radiotherapy has proved to be the most effective therapeutic approach, nevertheless, chemotherapy is also needed in advanced disease $(5,6)$. This article deals with a patient with dysphagia and limitation of neck movement resulting from a huge cervical metastasis of NPC. We describe this case in details regarding clinical presentation, histology, medical imaging and therapeutic regimen.

\section{Case report}

In March 2011, a 23-year-old Chinese man with severe malnutrition was admitted to the Department of Oral and Maxillofacial Surgery Sun Yat-sen Memorial Hospital of Sun Yat-sen University, Guangzhou, China. He had a 19-month and 16-month history of progressively enlarging mass in the left neck and right neck, respectively. The cervical mass had undergone a rapid increase in size and firmness over the previous 1.5 months and was accompanied by presence of dysphagia and limitation of neck movement but no symptoms of headache, dyspnea, nasal occlusion or blood-stained nasal discharge.

On physical examination, a firm, fixed, non-tender, and lobulated tumor was palpable in left cervical levels II, III, which was measured $15 \times 10 \times 7 \mathrm{~cm}$ with non-defined boundary. Meanwhile, physical examination revealed the other hard tumor on the right cervical level II which was measured $7 \times 6 \times 6 \mathrm{~cm}$ (Figures $1 \mathrm{~A}$ and B). There was a slight flushing of the skin in the cervical region but no papules were found and there were no phanerous lesions in the oral cavity, parotid glands and submaxillary glands.

The usual pre-operative work-up was implemented. Computerized tomography (CT) of the head and neck showed thickening of the soft tissue in posterior nasopharynx and enlarging nodes in the left parapharyngeal space. In two sides of the neck, multiple cystic lesions were found; most of them were $14 \times 10 \mathrm{~cm}$ in size (Figures $2 \mathrm{~A}$ and B). The CT scans of the chest, abdomen, and pelvis found no evidence of primary malignancy or metastatic disease. Therefore, NPC as the initial diagnosis was considered. Then, pharyngorhinoscopy was applied and showed neoplasm in the nasopharynx, while biopsy revealed undifferentiated non-keratinizing carcinoma (Figure 4A). For blood test, moderate anemia was found and no infectious disease was detected, such as HIV.

To relieve symptoms, a selective neck dissection was performed on the neck bilaterally. In the left neck, dissection included levels I, II, III and IV, while the sternocleidomastoid (SCM) muscle and internal jugular vein was sacrificed because of tumor infiltration (Figure 3). Meanwhile, lympho adipose tissue and cervical mass of levels I, II and III were dissected away in the right neck. Subsequently, histopathological examination of bilateral cervical mass revealed undifferentiated non-keratinizing carcinoma (Figure 4B), which was later proven CKs, CK5/6, P63, Epstein-Barr virus-encoded RNA in situ hybridization (EBER ISH) positive (Figures $4 \mathrm{C}, \mathrm{D}, \mathrm{E}$ and $\mathrm{F}$ ), thus supporting NPC cervical lymph node metastasis. The final diagnosis of this case was nasopharyngeal non-keratinizing carcinoma $\mathrm{pT} 3 \mathrm{~N} 2 \mathrm{M} 0$ according to the 2002 American Joint Committee on Cancer (AJCC) staging dioterapija se pokazala kao najučinkovitiji terapijski pristup, no potrebna je i u slučaju napredovale bolesti $(5,6)$. U ovom članku opisuje se bolesnik s disfagijom i ograničenim kretnjama vrata kao posljedicama goleme metastaze NPK-a u vratu. Taj slučaj detaljno opisujemo s obzirom na kliničku sliku, histologiju, medicinsku sliku i terapijske postupke.

\section{Prikaz slučaja}

U ožujku 2011. godine u bolnicu je primljen 23-godišnji Kinez s teškom pothranjenošću i to na Odjel za oralnu i maksilofacijalnu kirurgiju Memorijalne bolnice Sun Yat-Sen Sveučilišta Sun Yat-Sen u Guangzhou u Kini. U njegovoj povijesti bolesti bilo je zabilježeno progresivno povećanje mase u lijevom dijelu vrata prije 19 mjeseci i u desnom dijelu prije 16 mjeseci. Masa u vratu brzo je rasla i postajala čvršća unatrag 1,5 mjeseci, a pratila ju je i pojava disfagije te ograničeno kretanje vrata, ali bez simptoma glavobolje, dispneje, začepljenja ili krvavog iscjetka iz nosa.

$\mathrm{Na}$ fizikalnom pregledu liječnik je palpirao čvrst, fiksirani, neprozirni i lobulirani tumor u lijevoj strani vrata na razini II i III, veličine $15 \times 10 \times 7$ centimetara s nedefiniranom granicom. $U$ međuvremenu je fizički pregled otkrio i drugi tvrdi tumor na desnoj razini vrata II, veličine $7 \times 6 \times 6$ centimetara (slike 1. a i b). Pojavilo se blago crvenilo kože u vratnoj regiji, ali nisu nađene papule i nije bilo vidljivih lezija u usnoj šupljini te na parotidnim i submaksilarnim žlijezdama.

Provedena je uobičajena prijeoperacijska obrada. Kompjutorizirana tomografija (CT) glave i vrata pokazala je zadebljanje mekog tkiva u stražnjem nazofarinksu i povećanje čvorova u lijevom parafaringealnom prostoru. $\mathrm{Na}$ objema stranama vrata pronađene su višestruke cistične lezije - većina je bila $14 \times 10$ centimetara (slike 2 . a i b). Na CT skenovima prsnog koša, trbuha i zdjelice nisu pronađeni dokazi o primarnoj malignosti ili metastatskoj bolesti. Zato je razmatran NPK kao početna dijagnoza. Nakon toga je obavljena faringorinoskopija i nalazi su pokazali novotvorinu u nazofarinksu, a biopsija nediferencirani karcinom koji nije keratinizirao (slika 4. a). Analizom krvi ustanovljena je umjerena anemija, ali nisu otkrivene infektivne bolesti, kao što je HIV.

$\mathrm{Na}$ vratu je obostrano obavljena selektivna disekcija radi ublažavanja simptoma. Na lijevoj strani disekcija je uključivala razine I, II, III i IV, a sternokleidomastoidni (SCM) mišić i unutarnja jugularna vena bili su žrtvovani zbog infiltracije tumora (slika 3.). U međuvremenu je na desnoj strani vrata disecirano limfno-adipozno tkivo i cervikalna masa razina I, II i III. Nakon toga je histopatološkim pregledom bilateralne mase cerviksa otkriven nediferencirani rak koji nije keratinizirao (slika 4. b), a poslije je i dokazan [CKs, CK5/6, P63, Epstein-Barrov virusno kodiran RNK, in situ pozitivna hibridizacija (EBER ISH) (slike 4. c, d, e i f)], čime je poduprta hipoteza o metastazi vratnog limfnog čvora NPK-a. Konačna dijagnoza u ovom slučaju glasi nazofaringealni nekeratinizirajući karcinom pT3N2M0 prema američkom Zajedničkom odboru za rak (AJCC) iz 2002. godine. Pacijent je tada bio podvrgnut istodobnoj dvomjesečnoj kemoterapiji. Trodimenzionalna radioterapija temeljena na CT-u primije- 

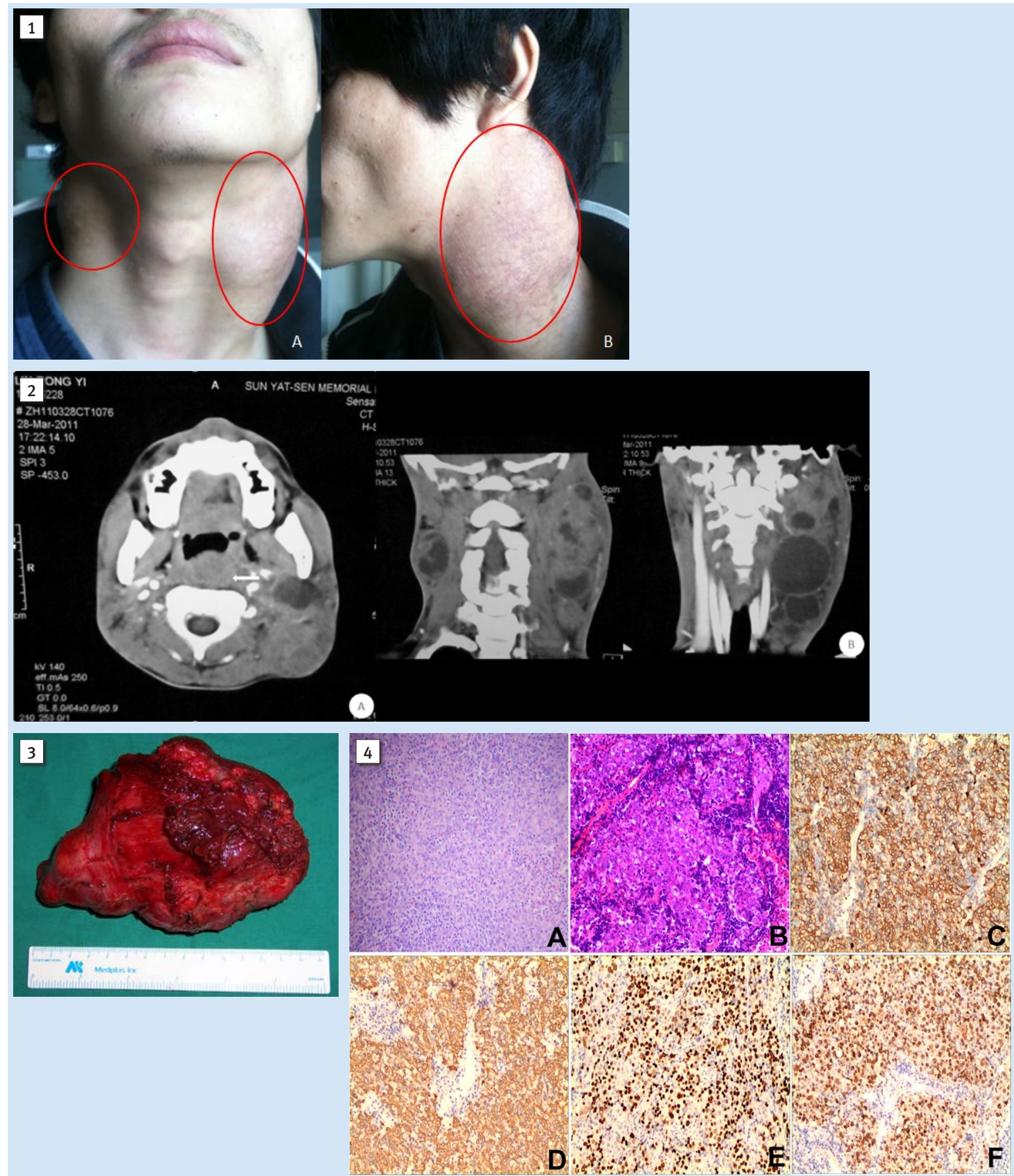

Figure 1 Preoperative front view (A) and profile (B) showing bilateral cervical enlarging mass.

Slika 1. Prijeoperacijski frontalni pogled (a) i profil (b) - vidi se obostrana povećana masa u vratu

Figure 2 Preoperative axial CT (A) at the level of the oropharynx showing parapharyngeal extension (arrow). Coronal CT (B) showing multiple cystic lesions in bilateral neck.

Slika 2. Prijeoperacijski aksijalni CT (a) na razini orofaringsa na kojemu se vidi parafaringealno proširenje (strelica); koronarni CT (b) prikazuje višestruku obostranu cističnu leziju u vratu

Figure 3 Surgical resection of left cervical mass with a length $14.5 \mathrm{~cm}$.

Slika 3. Kirurška resekcija lijeve mase u vratu u dužini od 14,5 centimetara

Figure 4 Histopathological examination of NPC with bilateral enormous cervical lymph nodes metastasis. (A),B) Hematoxylin and eosinstaining of primary nasopharyngeal carcinoma and left cervical lymph nodes metastasis, respectively. (C), (D), (E), (F) revealing CKs, CK5/6, P63, EBER expression was positive in left cervical lymph nodes metastasis (magnification $200 \mathrm{X}$ ).

Slika 4. Histopatološka analiza NPK-a s obostranim golemim metastazama vratnih limfnih čvorova; hematokslinsko i eozinsko bojenje primarnog nazofaringealnog karcinoma (a) i lijeve metastaze u vratnom limfnom čvoru (b); (c), (d), (e), (f) prikazuju CKs, CK5/6, P63, EBER pozitivni izričaj u lijevoj metastazi vratnoga limfnog čvora (povećanje 200 x) 
system. ${ }^{7}$ The patient then underwent concurrent chemo radiotherapy during a two-month period. The CT-based threedimensional radiotherapy was given with a total dose of 66 Gy delivered to the primary tumor and 60 Gy to bilateral neck metastatic areas, while concurrently a $40 \mathrm{mg} / \mathrm{m} 2$ dose of cisplatinum was administered weekly.

There was no evidence of persistent malignancy in primary tumor or any recurrence in cervical areas, one month after completion of the definitive treatment. The patient was in good condition at the time of the last follow up in December 2016 and was living a normal life.

\section{Discussion}

The majority (75-90\%) of newly diagnosed NPC patients have loco-regionally advanced disease, commonly with nodal metastases (1). Retropharyngeal nodes are the first echelons of nodal metastases for NPC while internal jugular nodes are the most frequently involved non-retropharyngeal nodes (72\%), (3,7). Superior deep cervical lymph nodes are the most common area of involvement, with directed spread reaching or occasionally jumping to the supraclavicular region. In a study of 101 patients, $\mathrm{Ng}$ et al. reported that the incidence of level II, III and IV cervical lymph node metastases was $95.5 \%, 60.7 \%$ and $34.8 \%$, respectively (8). In a study of 104 cases, Chow et al. reported that the largest size of metastatic cervical lymph nodes of NPC was $10 \mathrm{~cm} .{ }^{9}$ Therefore, the case of the patient with bilateral enormous cervical lymph nodes metastasis described in this report is extremely rare and the patient was only complaining about dysphagia and limitation of neck movement.

Histologically, NPC is subdivided into three types: keratinizing squamous cell carcinoma differentiated non-keratinizing carcinoma, undifferentiated non-keratinizing carcinoma and basal-like squamous cell carcinoma. Undifferentiated non-keratinizing carcinoma is the most common in Southern China (95\% of patients, which has been shown to have high correlation with EBERISH positivity $(8,10)$. EBER ISH has been well-described and used to confirm systemic metastases of NPC $(10,12)$. Ngan et al. propose one could argue about another unknown primary cancer as a potential source of metastasis if there is no EBER ISH confirmation (11). In the present case, the final histopathological examination showed that the bilateral enormous cervical lymph nodes metastasis was EBER positive and supported the NPC metastasis. Generally, non-keratinizing carcinomas have better primary tumor control rates and nodal control rates than keratinizing squamous cell carcinoma, while the latter group has a poorer survival rate than former group because of higher incidence of deaths from uncontrolled primary tumors and nodal metastases (13). The present case was identified undifferentiated non-keratinizing carcinoma in primary tumor and cervical mass. The patient received concurrent chemo radiotherapy after bilateral neck dissection and no tumor recurrence or metastasis was found in a 67 months fellowup. Nevertheless, metastatic cervical nodes from NPC are more readily controlled than cervical nodes of similar size arising from other head and neck squamous cell carcinomas njena je $s$ ukupnom dozom od 66 greja (Gy) koja je primljena u primarni tumor i 60 greja (Gy) na obostrane metastatske dijelove vrata, a istodobno je određeno i $40 \mathrm{mg} / \mathrm{m}^{2}$ doze cisplatina na tjedan.

Nije bilo dokaza o postojanom malignitetu primarnog tumora ili bilo kakvog recidiva u cervikalnim područjima, mjesec dana nakon završetka konačnog liječenja. Pacijent je bio u dobrom stanju u vrijeme posljednjeg praćenja u prosincu 2016. i živio je normalan život.

\section{Rasprava}

Većina novodijagnosticiranih bolesnika s NPK-om (75 - 90 \%) ima lokalno-regionalno napredovalu bolest, obično s metastazama limfnih čvorova (1). Retrofaringealni čvorovi prvi su ěsaloni nodalnih metastaza kad je riječ o NPK-u, a najčešće uključeni neretrofaringealni čvorovi su unutarnji jugularni čvorovi $(72 \%)(3,7)$. Gornji duboki limfni čvorovi najčešći su dio zahvata, $s$ usmjerenim širenjem koje doseže ili povremeno prelazi u supraklavikularnu regiju. $U$ istraživanju 101 pacijenta, $\mathrm{Ng}$ i suradnici istaknuli su da je učestalost metastaza cerviksa na razini II, III i IV bila 95,5\%, 60,7 \%, odnosno $34,8 \%$ (8). U studiji o 104 slučaja, Chow i suradnici izvijestili su da je najveća veličina metastatskih limfnih čvorova NPK-a 10 centimetara (9). Zato je slučaj bolesnika s obostrano golemim metastazama limfnih čvorova opisan u ovom izvješcu iznimno rijedak, a pacijent se žalio samo na disfagiju i ograničene kretnje vrata.

Histološki se NPK dijeli na tri oblika - karcinom pločastih stanica keratiniziranih diferenciranih karcinoma koji nisu keratinizirani, nediferencirani karcinom koji nije keratiniziran i karcinom bazalnog tipa pločastih stanica. Nediferencirani karcinom koji nije keratiniziran najčešći je u južnoj Kini. Kod $95 \%$ bolesnika, za koje se pokazalo da imaju visoku korelaciju s pozitivnošću EBER ISH-a $(8,10)$. EBER ISH je dobro opisan i korišten kad je riječ o potvrdi sustavnih metastaza NPK-a $(10,12)$. Ngan i suradnici predložili su da se raspravlja o još jednom nepoznatom primarnom raku kao potencijalnom izvoru metastaza, ako ne postoji potvrda EBER ISH-a (11). U ovom slučaju, konačni histopatološki pregled pokazao je da su bilateralno goleme metastaze limfnih čvorova bile EBER pozitivne i podupirale su stajalište o metastazama NPK-a. Općenito, nekeratinizirajući karcinomi imaju bolju stopu kontrole primarnoga tumora i stopu nodalne kontrole negoli keratinizirajući karcinom pločastih stanica, a druga skupina ima lošiju stopu preživljavanja od prve zbog veće smrtnosti od nekontroliranih primarnih tumora i metastaza čvorova (13). U ovom slučaju identificiran je nediferencirani karcinom koji nije keratinizirao u primarnom tumoru i masi vrata. Pacijent je primio istodobnu kemoterapiju nakon obostrane disekcije vrata i nije bilo recidiva ili metastaza tumora tijekom 67-mjesečne kontrole. Ipak, metastatski vratni čvorovi iz NPK-a lakše se kontroliraju negoli cervikalni slične veličine koji nastaju od drugih karcinoma pločastih stanica glave i vrata (9). Većina nedavnih istraživanja jasno je pokazala da NPK više nije problematična bolest 
(9). Most of recent studies have clearly demonstrated that NPC is no longer a problematic disease from a loco-regional control, based on the current standard treatment approach which consists of concurrent chemo-radiotherapy with cisplatin-based regimens, generally followed by adjuvant chemotherapy $(14,16,17)$.

Although surgical resection has a limited role in metastasis of NPC, there are some cases of advanced disease with a reasonable outcome after resection $(11,18,19)$. The patient in our report presented with dysphagia and a limitation of neck movement at diagnosis. We performed a selective neck resection of metastatic cervical mass as primary treatment. He received a good symptomatic relief which was helpful for improving defective nutrition condition and for building confidence for further treatment.

\section{Conclusions}

In conclusion, our patient had a bilateral enormous cervical metastasis from NPC which was resulting in significant clinical symptoms at the time of diagnosis. First, we performed an aggressive surgical resection for cervical mass, followed by concurrent chemo-radiotherapy; the comprehensive treatment regimen reached a reasonable outcome in such a case of advanced disease.

\section{Conflict of interest}

The authors report no conflict of interest. ako se obavlja lokalno-regionalna kontrola zasnovana na trenutačnom standardnom pristupu liječenju koje se sastoji od istodobne kemoterapije i terapije na bazi cisplatina te je općenito prati adjuvantna kemoterapija $(14,16,17)$.

Iako kirurška resekcija ima ograničenu ulogu u metastaziranju NPK-a, postoje neki slučajevi napredovale bolesti s razumnim ishodom nakon resekcije $(11,18,19)$. Pacijent u našem izvješću imao je disfagiju i ograničene pokrete vrata pri postavljanju radne dijagnoze. Kao primarno liječenje obavljena je selektivna resekcija metastatske mase u vratu. To je omogućilo simptomatsko olakšanje koje je bilo korisno za poboljšanje loše prehrane i za stvaranje povjerenja za daljnje liječenje.

\section{Zaključci}

Naš je pacijent imao obostrano golemu metastazu vrata koja je rezultirala značajnim kliničkim simptomima pri postavljanju dijagnoze. Najprije smo obavili agresivnu kiruršku resekciju mase u vratu, nakon čega je slijedila istodobna kemoterapija. Sveobuhvatnim liječenjem NPK-a postignut je razuman ishod u tom slučaju napredovale bolesti.

\section{Sukobi interesa}

Autori nisu bili u sukobu interesa.

\section{Sažetak}

Dok nazofaringealni karcinom (NPK) obično prate limfoidne metastaze, golema cervikalna metastaza koja uzrokuje disfagiju i ograničava pokrete vrata nije uobičajen simptom za većinu slučajeva NPK-a. Opisan je slučaj 23-godišnjeg muškarca s nediferenciranim rakom nazofarinksa stupnja T3N2MO, koji je prvi put bio podvrgnut agresivnoj kirurškoj bilateralnoj resekciji velike mase $u$ vratu, nakon čega je slijedila istodobna kemo- i radioterapija s terapijama na temelju cisplatina. Postoperativni klinički tijek bio je bez osobitosti, a na kontroli dvije godine poslije nije otkrivena ponovna pojava ni primarne lezije, ni metastaze u vratu. Ako bolesnici s NPK-om pate od kliničkih simptoma zbog velikih metastaza u vratu, preporučujemo da se u obzir uzme agresivna kirurška resekcija.
Zaprimljen: 12. prosinca 2018.

Prihvaćen: 11. travnja 2019.

Adresa za dopisivanje

Dr. Song Fan,

Sun Yat-Sen University, Sun Yat-Sen Memorial Hospital

Department of Oral and Maxillofacial

Surgery,

Guangzhou 510120, China.

tel: +8602081332220 ;

fansong8888@163.com or

Professor Eduardo Dias-Ribeiro, Federal University of Campina Grande Department of Dentistry,

Patos 58708110, Brazil.

tel: +55 83999031968 ;

eduardodonto@yahoo.com.br

Ključne riječi

nazofaringealni karcinom, metastaze $u$

vratu, resekcija

\section{References}

1. Vokes EE, Liebowitz DN, Weichselbaum RR. Nasopharyngeal carcinoma. Lancet. 1997 Oct 11;350(9084):1087-91.

2. Wei WI, Sham JS. Nasopharyngeal carcinoma. Lancet. 2005 Jun 11-17;365(9476):2041-54.

3. Ng SH1, Chang TC, Ko SF, Yen PS, Wan YL, Tang LM. Nasopharyngeal carcinoma: MRI and CT assessment. Neuroradiology. 1997 Oct;39(10):741-6

4. King AD1, Ahuja AT, Leung SF, Lam WW, Teo P, Chan YL. Neck node metastases from nasopharyngeal carcinoma: MRI of patterns of disease. Head Neck. 2000 May;22(3):275-81.
5. Kam MK, Teo PM, Chau RM. Treatment of nasopharyngeal carcinoma with intensity modulated radiotherapy: the Hong Kong experience. Int J Radiat Oncol Biol Phys. 2004;60:1440 - 1450.

6. Ma BB, Chan AT. Recent perspectives in the role of chemotherapy in the management of advanced nasopharyngeal carcinoma. Cancer. 2005 Jan 1;103(1):22-31.

7. Green FL, Page DL, Fleming ID - editors. American Joint Committee on Cancer Staging Manual, 6th ed. New York: Springer; 2002. p. 63.

8. Ng SH, Chang JT, Chan SC, Ko SF, Wang HM, Liao CT, et al. Nodal metastases of nasopharyngeal carcinoma: patterns of dis- 
ease on MRI and FDG PET. Eur J Nucl Med Mol Imaging. 2004 Aug;31(8):1073-80.

9. Chow E, Payne D, Keane T, Panzarella T, Izard MA. Enhanced control by radiotherapy of cervical lymph node metastases arising from nasopharyngeal carcinoma compared with nodal metastases from other head and neck squamous cell carcinomas. Int J Radiat Oncol Biol Phys. 1997 Aug 1;39(1):149-54.

10. Tsai ST, Jin YT, Su IJ. Expression of EBER1 in primary and metastatic nasopharyngeal carcinoma tissues in situ hybridization. A correlation with WHO histologic subtypes. Cancer. 1996 Jan $15 ; 77(2): 231-6$

11. Ngan RK, Yiu HH, Cheng HK, Chan JK, Sin VC, Lau WH. Central nervous system metastasis from nasopharyngeal carcinoma: a report of two patients and a review of the literature. Cancer. 2002 Jan 15;94(2):398-405.

12. Ho CL, Lee SH, Chen LM, Chao TY. Epstein-Barr virus early ribonucleic acids as a diagnostic adjunct for relapsed metastatic tumors in patients with cured primary undifferentiated nasopharyngeal carcinoma. Am J Otolaryngol. 2000 Mar-Apr;21(2):80-4.

13. Reddy SP, Raslan WF, Gooneratne S, Kathouria S, Marks JE. Prog nostic significance of keratinization in nasopharyngeal carcinoma. Am J Otolaryngol. 1995 Mar-Apr;16(2):103-8.

14. Wee J, Tan EH, Tai BC, Wong HB, Leong SS, Tan T, et al. Randomized trial of radiotherapy versus concurrent chemoradiotherapy followed by adjuvant chemotherapy in patients with American Joint Committee on Cancer/International Union against cancer stage III and IV nasopharyngeal cancer of the endemic variety. J Clin Oncol. 2005 Sep 20;23(27):6730-8.

15. Lee AW1, Sze WM, Au JS, Leung SF, Leung TW, Chua DT, et al. Treatment results for nasopharyngeal carcinoma in the modern era: the Hong Kong experience. Int J Radiat Oncol Biol Phys. 2005 Mar 15;61(4):1107-16

16. Hui EP, Leung SF, Au JS, Zee B, Tung S, Chua D, et al. Lung metastasis alone in nasopharyngeal carcinoma: a relatively favorable prognostic group. A study by the Hong Kong Nasopharyngeal Carcinoma Study Group. Cancer. 2004 Jul 15;101(2):300-6.

17. Razak AR, Siu LL, Liu FF, Ito E, O’Sullivan B, Chan K. Naso pharyngeal carcinoma: the next challenges. Cancer. 2004 Jul 15;101(2):300-6

18. Delis S, Biliatis I, Bourli A, Kapranos N, Dervenis C. Surgical re section of a solitary liver metastasis from nasopharyngeal carcinoma: a case report. Hepatobiliary Pancreat Dis Int. 2006 Nov;5(4):610-2.

19. Weitz J, Blumgart LH, Fong Y, Jarnagin WR, D’Angelica M, Harrison LE, et al. Partial hepatectomy for metastases from noncolorectal, nonneuroendocrine carcinoma. Ann Vasc Surg. 2017 Oct;44:269276. 